\title{
Fixing nature's mistakes on the aortic valve: Will the normal form ensure normal function in the long term?
}

\author{
Mario Gaudino, MD, and Christopher Lau, MD
}

\author{
From the Department of Cardiothoracic Surgery, Weill Cornell Medicine, New York, NY. \\ Disclosures: Authors have nothing to disclose with regard to commercial support. \\ Received for publication Nov 22, 2017; accepted for publication Dec 4, 2017; available ahead of print Jan 12, \\ 2018 \\ Address for reprints: Mario Gaudino, MD, Department of Cardiothoracic Surgery, Weill Cornell Medicine, $525 \mathrm{E}$ \\ 68th St, Suite M-404, New York, NY 10165 (E-mail: mfg9004@med.cornell.edu). \\ J Thorac Cardiovasc Surg 2018;155:942 \\ $0022-5223 / \$ 36.00$ \\ Copyright (C) 2017 by The American Association for Thoracic Surgery \\ https://doi.org/10.1016/j.jtcvs.2017.12.037
}

Human embryogenesis is a fascinating and almost miraculous process that in 40 weeks leads from an embryo to a complete organism. Normal function is dependent upon normal configuration and the beauty of the natural form is appreciated not only by physicians but even by artists such as Leonardo da Vinci, who took a particular interest in the aortic valve and sinuses of Valsalva. ${ }^{1}$ However, the complex developmental transformation can sometimes deviate from normal and lead to an immense variety of congenital malformations. Among them, anomalies of the aortic valve represent the most common cardiac anomaly. Bicuspid aortic valves are most common, seen in $1 \%$ to $2 \%$ of the general population, but quadricuspid and monocuspid aortic valves are rarer. ${ }^{2}$

While valve anomalies may be associated with aortic insufficiency or stenosis, their presence may also be associated with changes in aortic blood flow patterns. With normal trileaflet aortic valves, cohesive laminar flow is seen. Other valve configurations are associated with marked flow derangement. Whether these flow abnormalities lead to future valvular or aneurysmal degeneration is unclear. ${ }^{3}$ In this issue of the Journal, Lorca and coauthors ${ }^{3}$ report on a rare case of quadricuspid aortic valve associated with severe aortic insufficiency. Through a complex combination of annuloplasty and leaflets rearrangement, the authors were able to transform the quadricuspid valve into a trileaflet structure, restoring normal function with minimal aortic insufficiency. Although aortic valve replacement remains the treatment of choice, comprising approximately three quarters of cases in larger series, a select number of patients may benefit from aortic valve repair. A variety of repair techniques have been used in the past, including

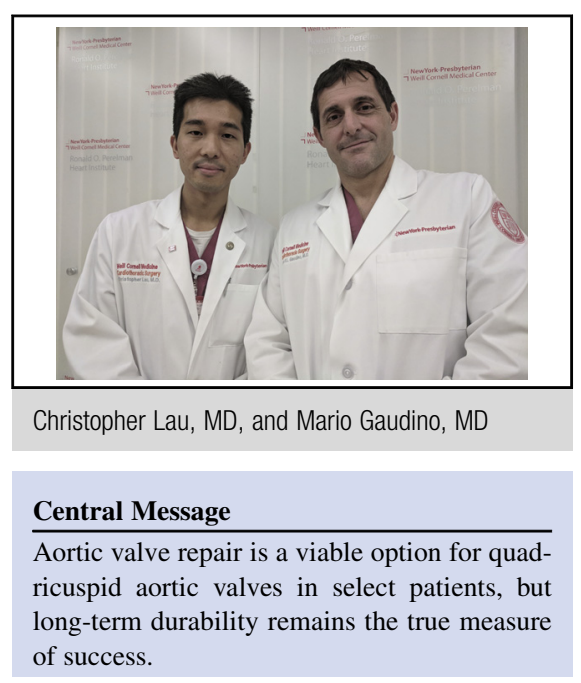

See Article page 940.

bicuspidization, resection of the fourth leaflet, and other complex valve reconstructions. ${ }^{4}$

The postoperative echocardiogram documented the excellent result of the repair, but clearly the real success of the operation will be judged only in the long-term follow-up. Given the young age and good functional status of the patient, the authors' efforts to preserve the native valve appear definitely appropriate. In aortic valve repair, as with much of the most prized artwork in the world, one may never know the true valve of the piece of art until many years have passed.

\section{References}

1. Robicsek F. Leonardo da Vinci and the sinuses of Valsalva. Ann Thorac Surg. 1991;52:328-35.

2. Entezari P, Schnell S, Mahadevia R, Malaisrie C, McCarthy P, Mendelson M, et al. From unicuspid to quadricuspid: influence of aortic valve morphology on aortic three-dimensional hemodynamics. J Magn Reson Imaging. 2014;40:1342-6.

3. Lorca R, Álvarez-Cabo R, Calvo J, de la Hera JM. Quadricuspid aortic valve surgical repair. J Thorac Cardiovasc Surg. 2018;155:940-1.

4. Idrees JJ, Roselli EE, Arafat A, Johnston DR, Svensson LG, Sabik JF III, et al. Outcomes after repair or replacement of dysfunctional quadricuspid aortic valve. J Thorac Cardiovasc Surg. 2015;150:79-82. 